\title{
Quantitatively Assessing Reported Crime versus Enrollment among Selected Higher Education Institutions
}

\author{
Daniel Doss ${ }^{1, *}$, Hilliard Lackey ${ }^{2}$, David McElreath ${ }^{3}$, Balakrishna Gokaraju $^{1}$, \\ Raymond Tesiero ${ }^{1}$, Don Jones ${ }^{4}$, Glenna Lusk ${ }^{3}$ \\ ${ }^{1}$ College of Business and Technology, University of West Alabama, Livingston, United States \\ ${ }^{2}$ College of Education, Jackson State University, United States \\ ${ }^{3}$ College of Applied Sciences, University of Mississippi, United States \\ ${ }^{4}$ Belhaven University, United States
}

Copyright $\bigcirc 2017$ by authors, all rights reserved. Authors agree that this article remains permanently open access under the terms of the Creative Commons Attribution License 4.0 International License

\begin{abstract}
This study uses multiple regressions to examine campus safety and campus security from the perspective of societal crime that occurs external to an institution of higher education versus institutional enrollment. The findings herein showed one statistically significant outcome involving the crime of aggravated assault. Student affairs and other institutional leaders may find this study useful when contemplating enrollment issues and Clery Act reporting requirements.
\end{abstract}

Keywords Campus Safety, Campus Security, Clery, Enrollment, Higher Education, Student Affairs

\section{Introduction}

Crime permeates the entirety of society, and is defined by society itself. Basically, crime is anything society says it is via the legislative process, codified and expressed as law, and made enforceable by proper authority $[1,2]$. The administrators and leaders of academic institutions are responsible for providing and maintaining safe environments to facilitate any activities that may occur within their respective campus boundaries. However, despite good faith and best efforts toward abating criminality, no institution of higher education is impervious to crime. All campuses must acknowledge the realities of both misdemeanors and felonies that may affect their respective academic settings.

\subsection{Clery Act}

During 1986, at Lehigh University, Jeanne Clery, an undergraduate student, was assaulted, raped, and killed in her dormitory. Although this attack resulted in her death, it was the catalyst for bolstering and enhancing campus safety and security throughout the entirety of the U.S. higher education system. The Crime Awareness and Campus Security Act of 1990 (Clery Act) resulted from this heinous crime. During modern times, the Clery Act mandates the reporting and disseminating publicly of crime data that reflects campus criminality. Such information is freely available to any parties that may have an interest in academic institutions.

Students of higher education institutions may not all live within the campus setting. Many also socialize and work outside the academic setting within surrounding communities. Although the Clery Act mandates the reporting of campus crimes, such external presences and activities may facilitate victimization of students that is never reported to campus law enforcement organizations. Given these notions, this study seeks to examine the potential interaction between such external criminality and institutional enrollment.

\subsection{Enrollment and Criminality}

Although anyone may review the crime data for an academic institution during the process of deciding which institution to attend, debate exists regarding whether knowledge and understanding of criminality affect enrollment decisions among higher education institutions. An examination of Virginia's higher education settings indicated that criminality may be explained significantly by the enrolled quantity of students residing "on campus" [3]. The study used correlation and data from the 2004 academic year to examine the complete "population of Virginia 4-year public, 4-year private, and 2-year public colleges and universities in the Commonwealth of Virginia" [3, p. 79]. Another study showed that the collegiate attendance decision is "less influenced by campus crime statistics" [4, p. 44]. This finding was based upon a study performed at a "mid-size university with a student population near 14,000" [4, p. 34]. The host research location was described as being 
similar to other institutions of higher education nationally [4].

Another study used regression to explore a national data set that spanned the period between 2000 and 2010 [5]. Among the examined settings, the typical levels of enrollment averaged approximately 15,361 students [5]. The study showed that enrollment is a direct determinant of criminality at higher education institutions [5]. A positive relationship exists between crime rates and enrollment rates [6]. This finding was based a study of 200 domestic institutions of higher education [6]. These institutions represented the first and fourth quartiles of increased enrollments for the period spanning the years 2007 and 2012 [6].

A 2003 study showed that crime knowledge significantly affected the choice to attend an institution of higher education [7]. This study examined a national data set containing a sample of 9,150 student respondents, a total of 3,866 usable responses, and a response rate of approximately $42 \%$ [7]. A contrasting study was discovered within the literature. Over a decade after the 2003 study, it was shown that crime knowledge was unlikely to affect the institutional attendance decision [8]. Using a student population of 16,200 and sample of 1,361 , the study generated this finding across multiple student categories, ranging from traditional students to "specialty college students such as medical and pharmacy residents" [8, p. 50].

Given the contents of the reviewed literature, little consensus exists to support a universal link between perceptions of reported criminality and enrollment existing among higher educations. Despite the disagreement expressed within the literature, none of the reviewed articles examined criminality versus enrollment from the perspective of land-grant institutions of higher education. Because of this absence within the reviewed literature, this article provides additional commentary regarding criminality versus enrollment from the perspective of land-grant institutions. Land-grant institutions are public, state-sponsored colleges and universities that originated with the Morrill Act of 1862 and the Morrill Act of 1890 [19]. Federal land was granted to the individual states wherein public institutions of higher education were created [19]. Historically, these institutions emphasized agricultural and mechanical disciplines as well as minority audiences (e.g., historically black colleges and universities) [19].

\subsection{Geospatial Perspective}

A 2012 study examined campus crime versus geospatial aspects of communities that surround higher education institutions [9]. Using a large, southern university, the study examined the period between 2003 and 2007 via a geospatial examination of 49,120 arrests involving university students [9]. The study showed that the Clery Act insufficiently portrays "victimization risk" because it excludes "incidents occurring very near, but technically not on college campuses" $[9$, p. 1150]. The study calls for greater awareness being generated regarding criminality that occurs near campuses beyond the minimum reporting mandates of the Clery Act [9]. Per the recommendation of the study, this article provides greater insight regarding the potential of societal instances of criminality to affect enrollments within the context of higher education institutions.

\subsection{Additional Attributes}

Other factors may affect collegiate choice and enrollment. Enrollment decisions may be affected by the reputations of academic programs and higher education institutions or by the offering of niche academic studies $[10,11]$. Factors affecting enrollment include education costs, financial aid, institutional size, geographic location, institutional appearance, and attentiveness by institutional personnel [12].

\subsection{Current Inquiry}

Institutional enrollment is of paramount importance for the longevity and survival of higher education institutions. Ensuring that a sufficient quantity of students exists to facilitate a financial breakeven point and profitability is a concern of academic administrators [13, 14]. Certainly, crime levels may affect enrollment [6, 7]. Criminal activity that occurs among the communities which surround campuses may affect academic settings of higher education institutions [9]. Because of such influences, it is recommended that institutional administrators provide information that exceeds the mandatory requirements of the Clery Act [9]. Given such notions, this study aims to examine the potential of societal criminality to affect enrollment quantities among higher education, land-grant institutions.

\subsection{Framework}

Maslow's needs hierarchy comprises the basis of this study. More specifically, the hierarchy addresses human safety and security needs. If these needs are not satisfied, then needs corresponding to knowing and understanding become uninfluential when considering learning and motivation [20]. Given this notion, campus safety and security needs among higher education institutions are of critical importance for administrators [21]. Thus, when considering the needs of campus safety and security, Maslow's hierarchy represents a theoretical foundation with respect to this study.

\section{Materials and Methods}

The design and method of this study represented a quantitative inquiry regarding the potential interaction between societal criminality and higher education institutional enrollment. The examined period ranged 
between the years 2001 and 2012. This period was selected because it provided the most recent reported crime data sets available from the U.S. Department of Education and the Federal Bureau of Investigation at the time of this study. Thus, this study represents a national analysis of secondary data that is accessible and freely available from the federal government.

\subsection{Data Sets}

The institutional enrollment data sets were obtained from the Campus Safety and Security database sponsored and maintained by the U.S. Department of Education. The data sets reflecting annual crime reports for each of the states were obtained from the Uniform Crime Reports (UCR) database sponsored and maintained by the Federal Bureau of Investigation. Given these sources, the data sets consisted of reported annual societal crime quantities and reported annual enrollment quantities within the U.S. higher education system. All of the annual values incorporated herein were used in aggregate forms.

\subsection{Population and Sample}

The population and sample for this study represented land-grant universities within the U.S. higher education system. Land-grant institutions of higher education were selected as the population for examination because they are present among all 50 states thereby providing the basis for a national study of societal crime versus institutional enrollment among higher education institutions.

According to the Smithsonian Institution, a total of 105 land-grant institutions exist within the U.S. higher education system [15]. This quantity of higher education organizations comprised the overall population $(N=105)$ for the study. However, the data sources contained data only for states, but not U.S. territories and the District of Columbia. Thus, the sample herein represents only land-grant education institutions among the 50 states. Given the exclusion of territorial and District of Columbia institutions, a total of 99 entities $(n=99)$ comprised the sample within this study.

\subsection{Research Questions and Hypotheses}

The primary research question for this study was: Do reported incidents of societal assaults and sex crimes affect enrollment quantities among land-grant higher education institutions? Investigating this question necessitated the following two sub-questions: Is there a statistically significant interaction between reported societal incidents of aggravated assault crimes and enrollment? Is there a statistically significant interaction between reported societal incidents of sex crimes and enrollment?

The null hypotheses derived from these research questions were as follows:

$\mathrm{H}_{0,1}$ : No statistically significant interaction exists between reported societal incidents of aggravated assault crimes and institutional enrollment.
$\mathrm{H}_{0,2}$ : No statistically significant interaction exists between reported societal incidents of sex crimes and institutional enrollment.

\subsection{Variables and Analytical Method}

The dependent variable for this study consisted of enrollment among higher education institutions. The independent variables for this study consisted of reported incidents of aggregated sex crimes and reported incidents of aggravated assault crimes. These variables were selected because they represent domestic instances of moral turpitude that may be lethal (e.g., the Jeanne Clery incident). These dependent and independent variables were incorporated within multiple regression analysis to investigate each of the considered hypotheses. The significance level of hypothesis testing was .05 . The assessment of multicollinearity potential was accomplished via the examination of the Pearson correlation coefficient reflecting potential strengths of relationships between the two independent variables of reported sex crime aggregates versus reported aggravated assault aggregates. All quantitative analyses were performed using PSPP.

\subsection{Reliability and Validity}

The data sets used within this study were obtained from government sources, specifically the Campus Safety and Security Database sponsored and maintained by the U.S. Department of Education and the Uniform Crime reports sponsored by the Federal Bureau of Investigation, thereby enhancing reliability. The data sets were aggregated from reported instances of criminality that were generated among each separate land-grant institution of higher education (among each state) per the Clery Act. Thus, the accumulated data is assumed to be a truthful representation of campus criminality at each of the considered higher education institutions.

\section{Findings}

Demographics of the dependent variable (enrollment) reflecting the values of mean and standard deviation were as follows: $M=1,405,712.58 ; S D=61,098.72$. The mean and standard deviation attributes for reported incidents of societal sex crimes were as follows: $M=90,848.67 ; S D=$ 4,157.84. The mean and standard deviation attributes for reported incidents of societal aggravated assault crimes were as follows: $M=838,393.17 ; S D=50,674.27$.

Respectively, the multiple $R$ and $R^{2}$ values resulting from the regression analysis were 0.97 and 0.94 . Thus, these outcomes suggest a favorable goodness-of-fit regarding the regression analysis with approximately $94 \%$ of the variation in the dependent variable (enrollment quantities) being explainable by the examined independent variables (annual aggregates of sex crimes and aggravated assault crimes).

Figure 1, shown below, delineates the results of the regression analysis. 


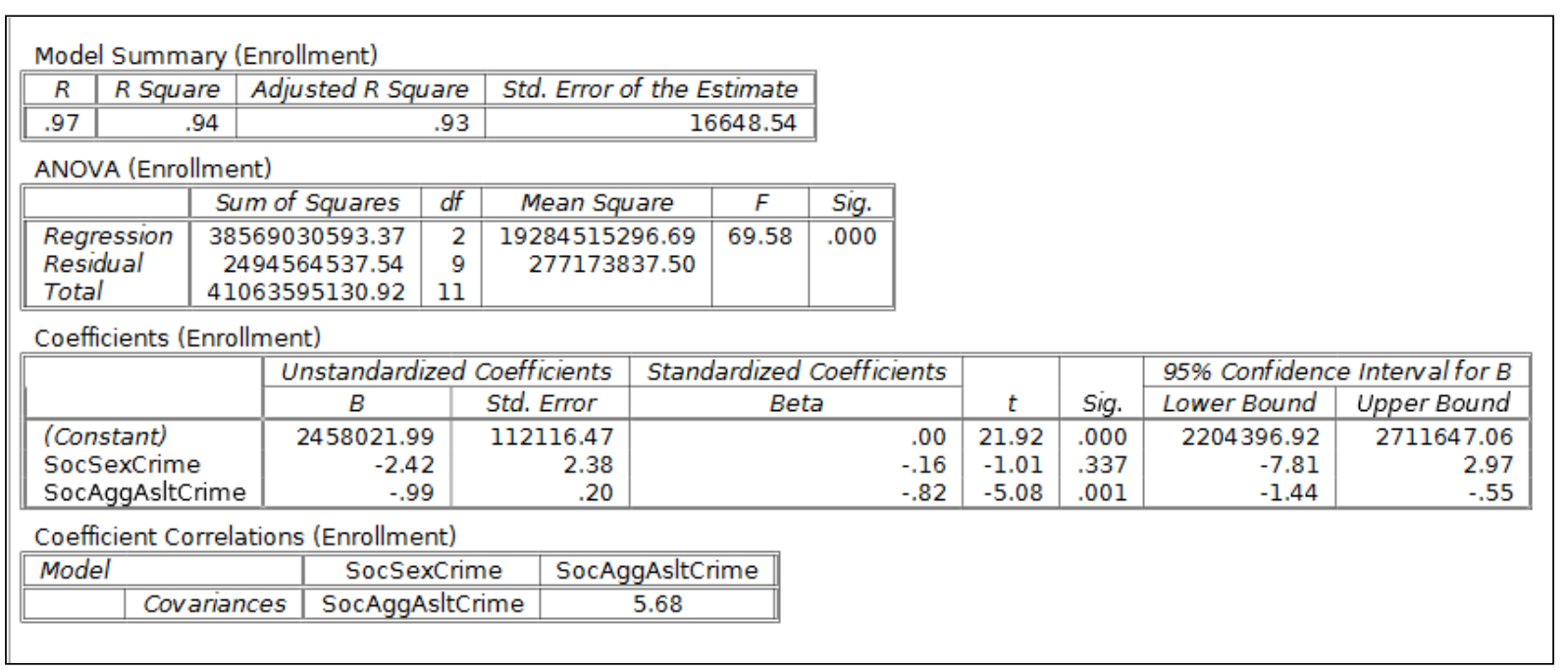

Figure 1. Regression Output

Given the contents of Figure 1, the hypothesis reflecting the notion that no statistically significant interaction exists between reported societal incidents of aggravated assault crimes and institutional enrollment is rejected $(p<.05)$. The hypothesis corresponding to the notion that no statistically significant interaction exists between reported societal incidents of sex crimes and institutional enrollment is retained $(p>.05)$. Thus, one statistically significant outcome was discovered via hypothesis testing involving the category of societal aggravated assault crimes.

Assessment of multicollinearity was accomplished through the use of correlation analysis. Using the Pearson correlation coefficient, the potential strength of relationship between the independent variables of reported incidents of sex crime aggregates versus reported incidents of aggravated assault crime aggregates was calculated as $r=$ 0.86 . Therefore, the potential of multicollinearity must not be discounted within the regression analysis of this study.

In addition to the regression analysis, the variables of sex crime aggregates and aggravated assault crime aggregates both may be examined separately with respect to their individual potential strengths of relationship regarding enrollment. Using correlation, the $r$ values of sex crime aggregates and aggravated assault crime aggregates are -0.87 and -0.97 , respectively. These outcomes indicate strong, negative potential strengths of relationships with enrollment. Essentially, in both cases, inverse relationships are suggested with enrollment.

\section{Conclusions and Recommendations}

The outcomes of this study provide insight regarding the potential of sex crime and aggravated assault crime within society to affect higher education enrollment. Although one must be mindful of collinearity, a statistically significant outcome was observed regarding aggravated assault crimes versus enrollment. This outcome may arise from perceptions of high-crime communities surrounding urban institutions of higher education as being unsafe for their residents, personnel, and visitors. For instance, in Memphis, Tennessee (an urban environment), among areas surrounding the campus of the University of Memphis, examples of criminality that affect the higher education settings include shootings, mugging, carjacking, disorderly conduct, assault, and robbery [16]. Another example involved a lethal, off-campus incident near Auburn University, Alabama in 2012. The city of Auburn is home to Auburn University (land-grant institution). The incident involved a deadly shooting at an apartment pool party that resulted in the deaths of three men [17]. Two of the decedents were affiliated with the institution's football team [17].

It is expected that colleges and universities are reasonably safe environments where individuals may work, students may learn, and others may visit. However, despite the best efforts to ensure campus safety and security, no higher education campus is impervious to threats involving assault and sex crimes (or any other type of crime). Campus safety and security are imperatives that must neither be discounted nor taken lightly by administrators. Instead, they must be of the highest importance to administrators as a measure of mitigating the risk of criminality. Given these notions, campuses may consider this study within the context of the emergency management cycle (EMC). The EMC is a cyclical process for managing incidents that may contribute toward the identifying of potential endangerments via the crafting and implementing of threat matrices [18]. The construction of threat matrices to identify and assign risks to various, perceived dangers is an EMC requirement for enhancing the ability of organizations to withstand perils [18]. When identifying potential threats, campuses may include criminality and corresponding threats that exists among localities surrounding the campus 
environment. Warnings may be issued commensurately when dangerous situations occur. Such activities would satisfy the recommendations of earlier research advocating the provision of a greater plethora of crime information to the public [9].

Although this study provides some insight throughout the initial decade of the twenty-first century, other studies may continue investigating the potential of criminality to affect enrollment among higher education institutions. The analyses contained herein examined criminality that occurs outside the boundaries of higher education settings with respect to its effects upon enrollment within higher education institutions. Future studies may examine a reflexive, internal view of criminality versus enrollment with respect to higher education institutions. Future studies may examine the interaction between various crime categories contained within the Campus Safety and Security database versus their potential interaction with institutional enrollment. For instance, various crimes, such as murder, manslaughter, assault, sex, robbery, and arson, may be examined with respect to potential interaction with enrollment. Certainly, additional crimes beyond the Campus Safety and Security database may be examined with respect to the potential interaction with institutional enrollment. Both internal and external perspectives of these crimes may be examined with respect to their enrollment effects among higher education institutions.

Another recommendation concerning future studies involves the population and sample. The population and sample of this study represented land-grant institutions of higher education. Future studies may examine other forms of higher education institutions, such as faith-based higher education institutions, historically black colleges and universities (HBCUs), Native American institutions, urban institutions, or sea-grant institutions. Regardless of the perspective, the basic context of this study may be examined among future endeavors: what is the interaction between criminality and enrollment?

\section{REFERENCES}

[1] D. McElreath, D. Doss, C. Jensen, M. Wigginton, R. Kennedy, $\mathrm{K}$ Winter, R. Mongue, J. Bounds, J. Estis-Sumerel. Introduction to law enforcement, CRC Press, Boca Raton, 2013.

[2] A. Goldstein \& J. Goldstein. Crime, law, and society. The Free Press, New York, 1971.

[3] Barnes, C.M. Examining campus crime at Virginia's colleges and universities. Virginia Commonwealth University, Richmond, 2009.

[4] B. Carrico. The effects of students' perceptions of campus safety and security on student enrollment. Marshall University, Huntington, 2016.
[5] J. Crouse. An economic analysis of campus crime and policing in the United States: An instrumental variables approach. European Scientific Journal, Vol. 10, No. 28, 50-73, 2014.

[6] B. Maurelli. From headlines to campuses: Exploring campus violence differences between campuses experiencing enrolment decline or growth. Capella University, Minneapolis, 2015.

[7] S. Janosik \& D. Gehring. The impact of the Clery Campus Crime Disclosure Act on student behavior. Journal of College Student Development, Vol. 44, No. 1, 81-91.

[8] J. Jee. The Clery Act: Student awareness and perception of effectiveness at a public university and a private college in East Tennessee. East Tennessee State University, Johnson City, 2016.

[9] M. Nobles, K. Fox, D. Khey, \& A. Lizotte. Community and campus crime: A geospatial examination of the Clery Act. Crime \& Delinquency, Vol. 59, No. 8, 1131-1156.

[10] D. Doss, D. Jones, W. Sumrall, R. Henley, D. McElreath, H. Lackey, \& B. Gokaraju. A net present worth analysis of considered academic programs at a private, regional higher education institution. Journal of Interdisciplinary Studies in Education, Vol. 4, No. 1, 55-77.

[11] D. Doss, R. Henley, D. McElreath, H. Lackey, D. Jones, B. Gokaraju, \& W. Sumrall. Homeland security education: Managerial versus nonmanagerial market perspectives of an academic program. Journal of Education for Business, Vol. 91, No. 4, 203-210.

[12] Why did they enroll? The factors influencing college choice: An analysis of traditional-aged students. Online available at: https://www.ruffalonl.com/documents/shared/Papers_and_Re search/2012/2012_Factors_to_Enroll.pdf

[13] N. Assie-Lumumba. Cyberspace, distance learning, and higher education in developing countries: Old and emergent issues of access, pedagogy, and knowledge production. Brill, Boston, 2004.

[14] M. Hedvicakova \& P. Maresova. Actual and future trends of the e-education and its costs specification in the Czech Republic. In K. Elleithy, T. Sobh, M. Iskander, M. Karim, \& A. Mahmood (eds) Technological developments in networking, education, and automation, Springer, New York, 2010.

[15] Smithsonian Institution. Campus and community. Online available from:

http://www.festival.si.edu/2012/campus-and-community/Smit hsonian

[16] University of Memphis. Personal safety alerts. Online available from:

http://www.memphis.edu/police/incidents/alerts.php

[17] Three killed in shooting near Auburn University. Online available from: http://www.nytimes.com/2012/06/11/ us/report-of-a-multiple-shooting-near-auburn-university.html

[18] D. McElreath, D. Doss, C. Jensen, M. Wigginton, R. Nations, J. Van Slyke, \& J. Nations. Foundations of emergency management. Kendall-Hunt, Dubuque, 2014.

[19] J. Thelin. A history of American higher education. The Johns Hopkins University Press, Baltimore, 2011. 
[20] D. Van Blerkom. Orientation to college learning. Wadsworth, Boston, 2013.
[21] D. Doss, H. Lackey, D. McElreath, D. Jones, R. Goza, \& J. Sheffield. Revisiting violence in rural academic settings: A school killing impacting Livingston High School and considerations of policy and programs. Vol. 16, No. 2, 156-191. 